\title{
Exclusion of one pedigree affected by adult onset primary open angle glaucoma from linkage to the juvenile glaucoma locus on chromosome 1q21-q31
}

\begin{abstract}
Dimitris Avramopoulos, George Kitsos, Effrosini Economou-Petersen, Maria Grigoriadou, Dimitris Vassilopoulos, Constantinos Papageorgiou, Konstantinos Psilas, Michael B Petersen
\end{abstract}

\begin{abstract}
A locus for autosomal dominant juvenile onset primary open angle glaucoma (POAG) was recently assigned to chromosome region 1q21-q31. In the present study, a large Greek family with autosomal dominant adult onset POAG was investigated using microsatellite markers. Exclusion of linkage of the adult onset POAG gene to the region D1S194-D1S191 was obtained in this pedigree. Therefore, the data provide evidence that juvenile and adult onset POAG are genetically distinct disease entities.

( $f$ Med Genet 1996;33:1043-1044)
\end{abstract}

Key words: glaucoma; autosomal dominant; linkage analysis.

Glaucoma is a leading cause of blindness worldwide. It is a heterogeneous group of disorders, the majority of which are associated with an open, normal appearing anterior chamber angle with normal trabecular meshwork and are termed primary open angle glaucoma (POAG). ${ }^{1}$ The relatively late age at onset of most forms of POAG has complicated the efforts to identify the mode of inheritance, but autosomal dominant inheritance has been described in families with juvenile $e^{2-4}$ as well as adult onset POAG. ${ }^{25-8}$
A locus for juvenile onset POAG (GLC1A) was recently assigned to the long arm of chromosome 1 in a large family with autosomal dominant inheritance, ${ }^{9}$ and confirmed in other families of juvenile onset. ${ }^{1011}$ The candidate region D1S194-D1S191 covers $23 \mathrm{cM}$ at 1q21q31. Analysis of recombinant haplotypes in the families reported improved the localisation of the gene responsible to a $10 \mathrm{cM}$ region (D1S196-D1S218)..$^{9-11}$ A huge pedigree has been reported with autosomal dominant POAG of either juvenile or adult onset, and the same haplotype between loci D1S196 and D1S212 was recognised in all affected subjects, suggesting a common locus for the juvenile and adult forms of POAG. ${ }^{12}$

In the present study, blood samples were collected from 50 members of one large pedigree identified in Epirus, Greece (fig 1) ${ }^{8}$ The clinical findings in affected subjects were consistent with adult onset POAG, including characteristic glaucomatous changes of the optic disc and visual field, increased cup to disc ratio, intraocular pressure commonly more than $30 \mathrm{mmHg}$ at the time of diagnosis, and no other signs of congenital or secondary glaucoma. The age at diagnosis was 30 years and older. The POAG in this family appears to be transmitted in an autosomal dominant fashion. Forty six people above 30 years of age were children of affected patients and therefore at $50 \%$ risk of

University Eye Clinic of Ioannina,

45110 Ioannina,

Greece

G Kitsos

K Psilas

Neurogenetics Unit, Department of Neurology, University of Athens,

11528 Athens,

Greece

E Economou-Petersen

D Vassilopoulos

C Papageorgiou

Thalassemia

Treatment Unit, Nikea

General Hospital,

18454 Nikea, Greece

E Economou-Petersen

Correspondence to:

Dr Petersen.

Received 16 February 1996

Revised version accepted for

publication 17 July 1996

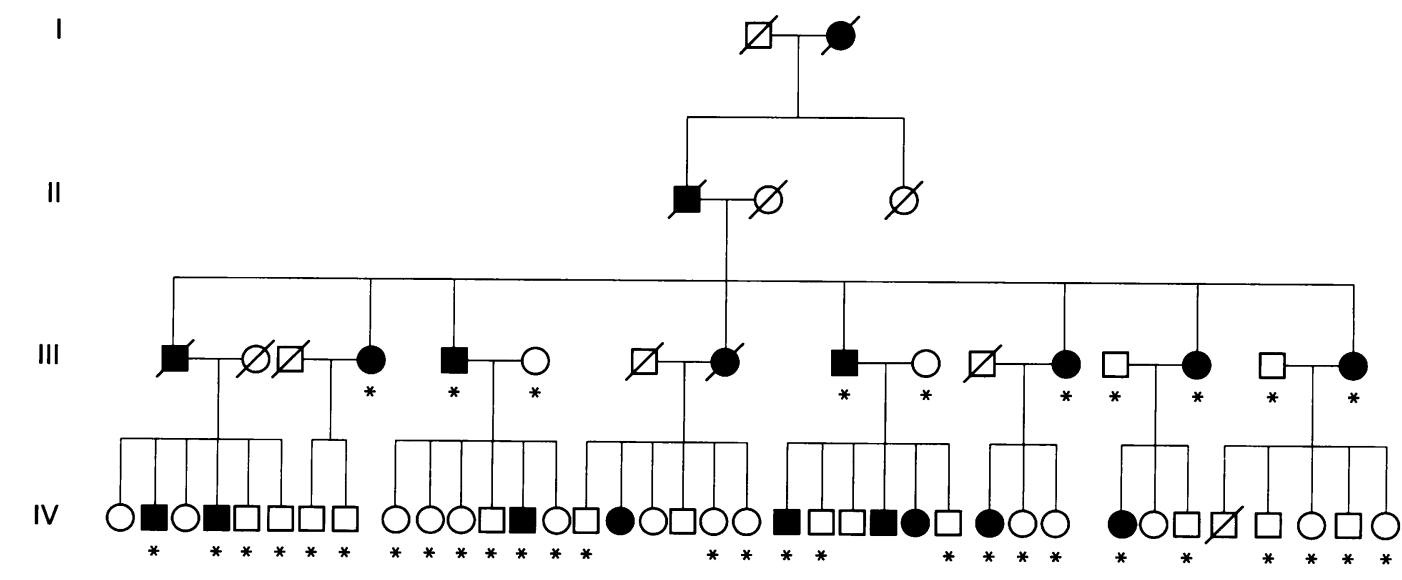

Figure 1 Adult onset primary open angle glaucoma segregating in a family from Epirus, Greece. Filled symbols indicate affected subjects. Only people above 30 years of age are shown. An asterisk indicates that the person was genotyped and used for linkage analysis. 
Table 1 Pairwise lod scores between adult onset POAG and chromosome 1q21-q31 microsatellites

\begin{tabular}{llllll}
\hline Locus & \multicolumn{5}{l}{ Lod scores at recombination fraction } \\
\cline { 2 - 6 } & 0.00 & 0.01 & 0.05 & 0.10 & 0.20 \\
\hline Penetrance $=1.00$ & -4.17 & -1.54 & -0.66 & -0.32 & -0.12 \\
D1S194 & $-\infty$ & -5.19 & -2.73 & -1.71 & -0.79 \\
D1S196 & $-\infty$ & -7.75 & -4.46 & -3.03 & -1.37 \\
D1S218 & $-\infty$ & -3.27 & -1.69 & -1.01 & -0.39 \\
D1S191 & & & & & \\
Penetrance $=0.78$ & -0.27 & -0.25 & -0.19 & -0.14 & -0.09 \\
D1S194 & -2.58 & -1.78 & -1.07 & -0.72 & -0.36 \\
D1S196 & -3.09 & -2.90 & -2.21 & -1.56 & -0.71 \\
D1S218 & -1.71 & -1.62 & -1.29 & -0.98 & -0.55 \\
D1S191 & & & & & \\
\hline
\end{tabular}

Table 2 Three point linkage analysis between adult onset $P O A G$ and chromosome 1q21-q31 microsatellites

\begin{tabular}{llll}
\hline Recombination distances & \multicolumn{2}{l}{ Lod scores under penetrance } \\
\cline { 2 - 4 } & & 1.00 & 0.78 \\
\hline D1S194-POAG-D1S196 & & \\
0.000 & 0.030 & -8.45 & -2.60 \\
0.006 & 0.024 & -7.87 & -2.62 \\
0.012 & 0.018 & -7.83 & -2.69 \\
0.018 & 0.012 & -8.09 & -2.81 \\
0.024 & 0.006 & -8.81 & -3.05 \\
0.030 & 0.000 & $-\infty$ & -3.99 \\
D1S196-POAG-D1S218 & & \\
0.000 & 0.090 & $-\infty$ & -2.84 \\
0.021 & 0.072 & -10.09 & -2.79 \\
0.040 & 0.054 & -9.98 & -2.78 \\
0.058 & 0.036 & -10.55 & -2.81 \\
0.075 & 0.018 & -11.74 & -2.96 \\
0.090 & 0.000 & $-\infty$ & -3.64 \\
D1S218-POAG-D1S191 & & \\
0.000 & 0.100 & $-\infty$ & -2.73 \\
0.024 & 0.080 & -7.80 & -2.41 \\
0.045 & 0.060 & -6.16 & -2.27 \\
0.065 & 0.040 & -5.43 & -2.23 \\
0.083 & 0.020 & -5.28 & -2.32 \\
0.100 & 0.000 & $-\infty$ & -2.43 \\
\hline
\end{tabular}

having inherited the disease causing mutation. Eighteen of these were found to be affected, which gives a calculated penetrance of $78 \%$ above 30 years of age.

Oligonucleotides flanking microsatellite DNA polymorphisms on human chromosome 1 were as published elsewhere. ${ }^{13}$ PCR amplification was performed according to a previously published protocol. ${ }^{14}$ Linkage between POAG and microsatellites was analysed using the computer program package LINKAGE version $5.1,{ }^{15}$ assuming autosomal dominant inheritance with a disease allele frequency of 0.01 , and using locus distances from the published genetic map of human chromosome $1 .{ }^{13}$ Only people above 30 years of age were included in the analysis (37 of 50 subjects) (fig 1). Lod scores were calculated under two models. The first model assumed full penetrance. The second model assumed a fixed penetrance of 0.78 above 30 years of age.

Pairwise lod scores between POAG and chromosome 1 microsatellites are shown in table 1 . Locus D1S218, which was completely linked in the three previous reports of juvenile onset POAG, ${ }^{9-11}$ shows exclusion of linkage in our pedigree both under a model assuming full penetrance and under a model assuming a fixed penetrance of 0.78 above 30 years of age. The exclusion distances for each marker under the full penetrance model was $15 \mathrm{cM}$ (D1S218), $7 \mathrm{cM}$ (D1S196), $3 \mathrm{cM}$ (D1S191), and less than $1 \mathrm{cM}$ (D1S194). Analysis of marker-marker linkage within the family was consistent with the published genetic linkage map ${ }^{13}$ (data not shown). The results of three point analysis are shown in table 2 . The subregions D1S194D1S196, D1S196-D1S218, and D1S218D1S191 are excluded in our family under both models. The data indicate that the POAG gene in our pedigree is highly unlikely to lie in the entire critical region on chromosome 1 (D1S196-D1S218) and suggest that genetic heterogeneity exists within the autosomal dominant form of POAG, providing evidence for at least one other autosomal locus.

In light of the distinct clinical features between juvenile onset and adult onset POAG, genetic heterogeneity as the cause of an eye disorder such as POAG is to be expected. Additional locus heterogeneity might be expected from reports consistent with autosomal recessive inheritance. ${ }^{16-18}$ It is hoped that further linkage analysis in this and other families will eventually result in the identification of the disease causing genes and thereby elucidate the pathogenesis of all types of POAG. The primers flanking microsatellite markers were kindly sup-
plied by Dr Claes Wadelius, University of Uppsala (supported by the Council of the Nordic Ministers).

1 Quigley HA. Open-angle glaucoma. N Engl f Med 1993; 328:1097-106.

Francois J. Genetics and primary open-angle glaucoma. $A m$ f Ophthalmol 1966;61:652-65.

Courtney RH, Hill E. Hereditary juvenile glaucoma simplex. ҰAMA 1931;97:1602-9.

4 Crombie AL, Cullen JF. Hereditary glaucoma. Occurrence in five generations of an Edinburgh family. Br f Ophthalmol 1964;48:143-7.

5 Posner A, Schlossman A. Role of inheritance in glaucoma Arch Ophthalmol 1949;41:125-50.

6 Stokes WH. Hereditary primary glaucoma. A pedigree with five generations. Arch Ophthalmol 1940;24:885-909.

7 Harris D. The inheritance of glaucoma. A pedigree of familial glaucoma. Am F Ophthalmol 1965;60:91-4.

8 Kitsos G, Côté G, Psilas K. Un exemple d'hérédité dominante pour la transmission du glaucome primitif à angle ouvert dans une région du nord-ouest de la Grèce. $\mathcal{F} F_{r}$ Ophtalmol 1988;11:859-64.

9 Sheffield VC, Stone EM, Alward WLM, et al. Genetic linkage of familial open angle glaucoma to chromosome linkage of familial open angle glaucom

10 Richards JE, Lichter PR, Boehnke M, et al. Mapping of a gene for autosomal dominant juvenile-onset open-angle glaucoma to chromosome 1q. Am F Hum Genet 1994;54 $62-70$.

11 Wiggs JL, Haines JL, Paglinauan C, Fine A, Sporn C, Lou D. Genetic linkage of autosomal dominant juvenile glaucoma to 1q21-q31 in three affected pedigrees. Gen omics 1994;21:299-303.

12 Morissette J, Côté G, Anctil JL, et al. A common gene for juvenile and adult onset primary open-angle glaucomas confined on chromosome 1q. Am 7 Hum Genet 1995;56: 1431-42.

13 Gyapay G, Morissette J, Vignal A, et al. The 1993-94 Genethon human genetic linkage map. Nat Genet 1994; 7:246-339.

14 Petersen MB, Economou EP, Slaugenhaupt SA, Chakravarti A, Antonarakis SE. Linkage analysis of the human A, Antonarakis SE. Linkage analysis of the human HMG14 gene on chromosome 21 using a GT dinucleotide

15 Lathrop GM, Lalouel JM. Easy calculations of lod scores and genetic risks on small computers. Am f Hum Genet and genetic risk

16 Waardenburg PJ. Is primary (pre)senile glaucoma repeatedly hereditary and, if so, what is the mode of hereditary transmission? Ophthalmologica 1950;119:250-2

17 Biro I. Notes upon the question of hereditary glaucoma Ophthalmologica 1951;122:228-38.

18 Beiguelman B, Prado D. Recessive juvenile glaucoma. $f$ Genet Hum 1963;12:53-4. 